\title{
Spatiotemporal heterogeneity and influencing mechanism of ecosystem services in the Pearl River Delta from the perspective of LUCC
}

\author{
ZHOU Rubo, "LIN Meizhen, GONG Jianzhou, WU Zhuo \\ School of Geographical Sciences, Guangzhou University, Guangzhou 510006, China
}

\begin{abstract}
Land use/land cover change (LUCC) has considerable impact on ecosystem services. It is essential to quantify the spatiotemporal heterogeneity of ecosystem services from the perspective of LUCC, which will benefit regional land management and ecological protection. We analyzed land use change in the Pearl River Delta from 2000 to 2015, and we used a spatially explicit integrated modeling tool (InVEST) for quantification of ecosystem services-water yield, carbon storage, soil retention, and food supply. The results revealed increases in the areas of grassland and built-up land, and decreases in the areas of woodland, cropland, water body, and unused land during 2000 to 2015, which have caused increase in water yield and carbon storage, while decrease in soil retention and food supply. The dynamic changes of woodland, grassland, cropland, and built-up land were the main driving factors in the relationship of trade-offs and synergies among the four ecosystem services, which are ubiquitous. Those all illustrate the importance of considering ecosystem services in decision making related to land use and land management.
\end{abstract}

Keywords: LUCC; ecosystem services; InVEST model; heterogeneity

\section{Introduction}

Ecosystem services represent the benefits derived directly or indirectly by living organisms from ecological functions that maintain the earth's life support system, including various products or services, e.g., fresh air and healthy food (Daily, 1997; Costanza et al., 1997). Consequently, ecosystem services constitute the foundation of human survival. However, with increasing population and increasing demand for materials, the destruction of the ecological environment by human beings has caused irreversible effects that have led to dramatic degradation of ecosystem services (Di Sabatino et al., 2013). According to the Millennium Ecosystem Assessment, approximately 63\% of ecosystem services have experienced severe decline over the past 50 years, and various ecosystem services are

Received: 2018-09-20 Accepted: 2019-01-20

Foundation: National Natural Science Foundation of China, No.41771097, No.41671175

Author: Zhou Rubo (1995-), Postgraduate, specialized in the study of ecosystem services. E-mail: 429732394@qq.com

"Corresponding author: Lin Meizhen, Professor, E-mail: 1mzh888@163.com 
forecast to continue to decline sharply over the next 50 years (MA, 2005). If ecosystem services could be developed and protected properly, the environment and living standards of human beings could improve. Conversely, failure to address this problem could seriously hinder normal activities of human beings and even bring about devastating disasters. Therefore, under the guidance of the common norms of "sustainable development," ecosystem services have become an area of active research in many disciplines (Fu et al., 2014).

The spatiotemporal heterogeneity of ecosystem services is a complex process that is influenced by both human and natural factors, e.g., climate change, agricultural production activities, and policy (Fu et al., 2009; Ouyang et al., 2016; Liu et al., 2018b). However, as the most direct manifestation of human activities, land use/land cover change (LUCC) has the most intense impact on ecosystem services over short timescales (Li et al., 2013). LUCC can affect atmospheric, water, and land systems directly, resulting in dynamic changes in the overall ecosystem services of a region (Vidal-Legaz et al., 2013). Therefore, as LUCC becomes the focus of research on global change, its impact on ecosystem services is also receiving increasing attention (Rodríguez et al., 2006). At present, research on the impact of land use change on ecosystem services is concentrated mainly in the following areas: the impact of different land use types on ecosystem services, the impact of changes in land use patterns on ecosystem services, and the impact of different land use intensities on ecosystem services (Fu et al., 2014). For example, Braat et al. (2008) emphasized that the supply of various types of ecosystem services was seriously threatened when human activities were particularly intense and caused land degradation. Fu et al. (2016) found that some local soil erosion has been successfully controlled due to the increase in vegetation with large-scale restoration measures on the Loess Plateau, but the entire regional ecosystem is still very fragile. Liu et al. (2018a) found that the conversion from cropland to grassland led to changes in the biophysical effects of regional climatic regulation in the typical study area of the Loess Plateau of China, which affected regional ecosystem services.

However, research on the impact of LUCC on the relationships among ecosystem services is lacking. The relationships among ecosystem services generally exhibit trade-offs and synergies (Peng et al., 2017). A trade-off refers to the reduction or loss of other ecosystem services when attempting to optimize a single service. A synergy occurs when the provisions of several ecosystem services increase or decrease simultaneously (Li et al., 2013). Land use decision making is usually intended to maximize an individual service, such as agricultural production or timber production, which could result in a decline in the provision of other services (MA, 2005). For example, if decision makers blindly pursue high production of grain, they will greatly increase the area of cultivated land and invade original natural green space, which eventually will lead to a decline in the capacity of soil retention. Therefore, the relationships of the trade-offs and synergies among various ecosystem services are in part driven by LUCC. In summary, it is important to understand how to manage the changes in ecosystem services driven by LUCC and land use management for regional sustainable development of the economy and ecology. 
Since the beginning of economic reforms in 1978, like many coastal cities, the Pearl River Delta has become one of the fastest growing regions in China and it has undergone dramatic changes in land use. According to the statistics, the rate of urbanization in the Pearl River Delta was $71.60 \%$ in 2000 and increased to $84.12 \%$ in 2015 (Zhou, 2015). The speed of urbanization in the Pearl River Delta during the past 15 years has not slowed down, which is rare in developed countries worldwide. Since 2000, ecosystems in the Pearl River Delta have been more seriously destroyed and degraded due to rapid urbanization and dramatic changes in land use (Wu et al., 2006; Yang, 2011). Widespread ecological and environmental problems like water pollution, soil erosion, and increased flooding have emerged, which have seriously hindered sustainable economic development (Xu et al., 2011). At the same time, local government is promoting the construction of the Guangdong-Hong Kong-Macao Greater Bay Area as a region for quality living and leisure. Because it is an important part of this area, the land management and ecological problems of the Pearl River Delta will have considerable impacts on the ongoing sustainable development of the regional economy. Therefore, this study aimed to explore the spatiotemporal heterogeneity of ecosystem services under the influence of LUCC in the Pearl River Delta and to provide a basis for ecological management and land use planning in the region. These aims were achieved via three analyses: (1) to quantify land use change in the Pearl River Delta from 2000 to 2015, (2) to characterize the spatiotemporal heterogeneity and mechanisms of ecosystem services (i.e., water yield, carbon storage, soil retention, and food supply) driven by land use change in the Pearl River Delta using the InVEST model, and (3) to understand the relationships of trade-offs and synergies among the above four ecosystem services in the Pearl River Delta from the perspective of LUCC using GeoDA software and spatial correlation analysis.

\section{Study area}

The Pearl River Delta, which is a complex delta formed by the sediments of the Xijiang, Beijiang, Dongjiang rivers and tributaries, is located in the southeast of Guangdong Province of China (Ye et al., 2013), covering an area of $53,900 \mathrm{~km}^{2}\left(21^{\circ} 17-24^{\circ} 24^{\prime} \mathrm{N}\right.$, $\left.111^{\circ} 59^{\prime}-115^{\circ} 25^{\prime} \mathrm{E}\right)$. The Pearl River Delta has a southern subtropical climate with abundant sunshine and rainfall. It has an average annual temperature of $21-23^{\circ} \mathrm{C}$ and the average annual precipitation of $1500 \mathrm{~mm}$. These conditions have enabled the people of the Pearl River Delta to create a special dike-pond environment that has become a model for China's eco-agriculture. In 2016, the permanent population of the Pearl River Delta was 57.2 million and the gross domestic product of the region was 9.2 billion yuan. The rapid regional economic development and eco-environmental problems of all the regional cities have affected the sustainable development of the Pearl River Delta. The resources and environment of the Pearl River Delta have been largely destroyed, and the eco-environmental function has been degraded considerably. For the purposes of this study, the area of the Pearl River Delta includes nine prefecture-level cities: Guangzhou, Shenzhen, Foshan, Dongguan, Huizhou, Zhongshan, Zhuhai, Jiangmen, and Zhaoqing (Figure 1). 


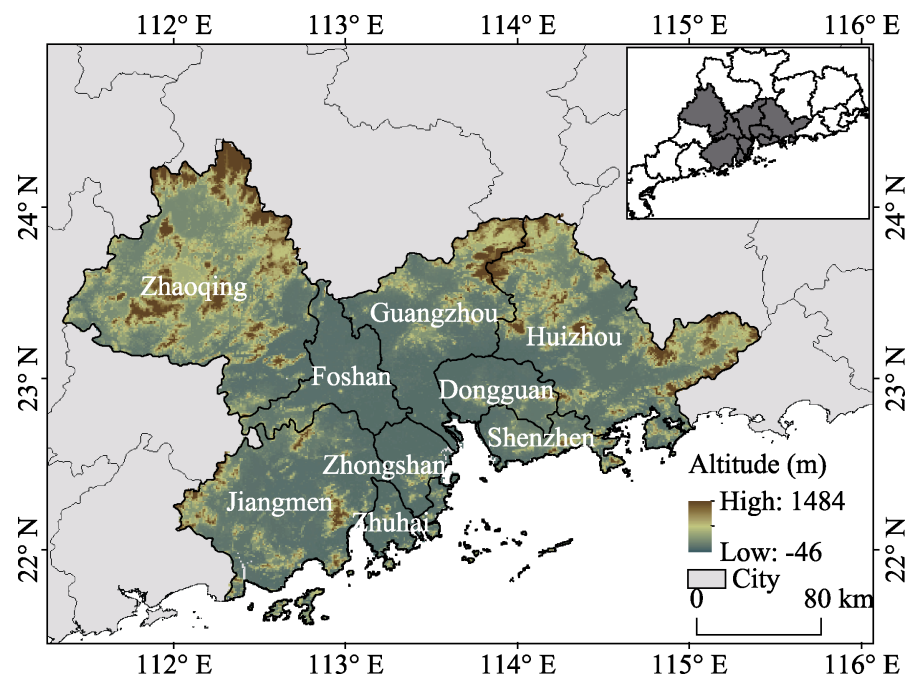

Figure 1 Location of the Pearl River Delta

\section{Materials and methodology}

\subsection{Data source and processing}

Considering the size and scale of the Pearl River Delta region, it is thought that land use data with a spatial resolution of $1 \times 1 \mathrm{~km}$ can meet the research requirements. Land use maps (spatial precision is $1 \times 1 \mathrm{~km}$ ) of the Pearl River Delta in 2000 and 2015 were downloaded from the Resource and Environment Data Cloud platform (http://www.resdc.cn). According to the research needs, the land use data were classified into six categories: cropland, woodland, grassland, water body, built-up land, and unused land. Precipitation data of the Pearl River Delta from 2000 to 2015 were acquired from the National Meteorological Information Center (http://data.cma.cn/). Then, according to the actual situation of the study area, Kriging spatial interpolation was used to obtain maps of the distribution of the annual average precipitation of the Pearl River Delta. A digital elevation model (DEM) with spatial resolution of $30 \mathrm{~m}$ is available from the international scientific data-mirroring website (http://www.gscloud.cn) of the Computer Network Information Center of the Chinese Academy of Sciences. After filling, flow analysis, and other processing procedures, digital elevation data that met the research needs were obtained. Soil data for this study were generated from the Soil Map of China based on the Harmonized World Soil Database (version 1.1, with a 1:1 million map scale), which was created by the Cold and Arid Regions Sciences Data Center in 2009 (http://westdc.westgis.ac.cn). Carbon density for each land use was collected from other results (Gan et al., 2003; Zhang et al., 2011; Wu et al., 2016) based on the principle of similarity within the natural environment of the Pearl River Delta.

\subsection{Methods}

\subsubsection{Ecosystem service evaluation}

This study applied the Integrated Valuation of Environmental Service and Tradeoffs (InVEST) model to evaluate ecosystem services. The InVEST model is an ecosystem services 
modeling toolset implemented in a GIS environment, which was developed by the Natural Capital Project (Tang et al., 2015). The InVEST model is a modular, open-source, free toolset in which tabular and spatial data are combined with stand-alone biophysical models to quantify, visualize, and compare the delivery of key ecosystem services (Butsic et al., 2017). The InVEST model can also be used to analyze the impact of land use and land management on ecosystem services because it requires land use data to run. By varying the conditions of land use or land management, evaluation of the InVEST model output can provide information useful to managers and policy makers required to weigh the trade-offs among ecosystem services and other land use objectives. In this study, we used the four submodels of ecosystem services (i.e., water yield, carbon storage, soil retention, and food supply) in the InVEST model version 3.4.4. The principles and calculation method of each submodel were as follows.

(1) Water yield. The water yield module is based on the Budyko curve (1974) and annual precipitation, and taking the climate, vegetation, and soil into account (the interaction between surface water and groundwater is not considered), it uses a grid as an evaluation unit to quantify the capacity of water yield of different landscapes. The formula is as follows:

$$
Y_{x j}=\left(1-\frac{A E T_{x j}}{P_{x}}\right) \times P_{x},
$$

where $Y_{x j}$ is the water yield (mm) at pixel $x$ of LULC $j, A E T_{x j}$ is the actual evapotranspiration (mm) at pixel $x$ of LULC $j$, and $P_{x}$ is the annual average precipitation (mm) at pixel $x$. This study used the Modified-Hargreaves formula of Droogers (2002) to calculate the annual average potential evapotranspiration for the 87 meteorological stations in the Pearl River Delta from 2000 to 2015 . Then, Kriging spatial interpolation was used to obtain a map of the annual average potential evapotranspiration of the Pearl River Delta.

(2) Carbon storage. The carbon module uses land use maps and the carbon density (i.e., aboveground biomass, belowground biomass, soil, and dead biomass) of each land use type to estimate the amount of carbon currently stored in a landscape. The formula is as follows:

$$
C_{\text {tot }}=\text { Cabove }+ \text { Cbelow }+C_{\text {soil }}+C_{\text {dead }}
$$

where $C_{\text {tot }}$ is the total carbon storage $(\mathrm{t})$, Cabove is the carbon storage $(\mathrm{t})$ in aboveground biomass, Cbelow is the carbon storage $(\mathrm{t})$ in belowground biomass, Csoil is the carbon storage ( $\mathrm{t}$ ) in soil, and $C_{\text {dead }}$ is the carbon storage $(\mathrm{t})$ in dead biomass. As the carbon storage of dead biomass is difficult to observe and its reserves are relatively small in comparison with the other terms, it was ignored in this study.

(3) Soil retention. The soil retention module, which is based on the Universal Soil Loss Equation (USLE), is used to estimate the amount of soil erosion within a region. This model takes into account the interception capabilities of the ground. The formula is as follows:

$$
\begin{gathered}
U S L E=R \times K \times L S \times C \times P, \\
R K L S=R \times K \times L S, \\
S D=R K L S-U S L E,
\end{gathered}
$$

where $R K L S$ is the total potential soil loss (t) per pixel in the original land cover without the application of factors $\mathrm{C}$ or $\mathrm{P}$ from the $R K L S$ equation (i.e., equivalent to the soil loss for bare soil), USLE is the total potential soil loss (t) per pixel in the original land cover calculated from the USLE equation, $S D$ is the amount of soil retention ( $\mathrm{t}$ ), and $R$ is the rainfall erosivity 
$\left(\mathrm{MJ} \cdot \mathrm{mm} /\left(\mathrm{hm}^{2} \cdot \mathrm{h} \cdot \mathrm{a}\right)\right)$. This study used the formula of Wischmeier (Wang et al., 1995) to calculate $R$ according to the average monthly precipitation and annual precipitation in the Pearl River Delta. In the above, $K$ is the soil erodibility $\left(\mathrm{t} \cdot \mathrm{hm}^{2} \cdot \mathrm{h} /\left(\mathrm{hm}^{2} \cdot \mathrm{MJ} \cdot \mathrm{mm}\right)\right)$ calculated using the EPIC formula (Sharpley et al., 1990) based on relevant soil data, $L S$ is the slope length gradient factor, $C$ is the cover management factor obtained by the FAO (Roose, 1996), and $P$ is the support practice factor that is available from the USDA Agriculture Handbook (Renard et al., 1997).

(4) Food supply. The food supply module is still in the testing stage and it cannot be applied fully. This study referred to its calculation principle that the capability of food supply can be expressed by the crop yield per unit of land area (Tallis et al., 2011). The formula is as follows:

$$
F_{(x)}=\frac{C Y(x)}{A(x)},
$$

where $F_{(x)}$ is the capability of food supply $\left(\mathrm{t} / \mathrm{km}^{2}\right), C Y_{(x)}$ is the food supply $(\mathrm{t})$ within the region, and $A_{(x)}$ is the area $\left(\mathrm{km}^{2}\right)$ of the region.

\subsubsection{Calculation of the ecological services change index}

To assess the temporal change of ecosystem services in the Pearl River Delta from 2000 to 2015, an ecosystem service change index (ESCI) (Leh et al., 2013) was introduced for the evaluation, and the results were spatialized using ArcGIS 10.2. The ESCI can determine and map ecosystem services states as time and location-dependent variables that quantify a particular service at a particular time. The ESCI indicates an increase in ecosystem service when $\mathrm{ESCI}>0$, it represents a decrease when ESCI $<0$, and it indicates no change when $\mathrm{ESCI}=0$. The formula is as follows:

$$
\operatorname{ESCI} x=\frac{E S \operatorname{CUR}_{x}-E S_{\mathrm{HIS}} x}{E S_{\mathrm{HIS}} x},
$$

where $\mathrm{ESCI}_{x}$ is the ecosystem service change index of $x ; E S \mathrm{CUR} x$ is the current ecosystem service state value of service $x$, and $E S$ HIS $_{x}$ is the historic ecosystem service state value of service $x$.

\subsubsection{Quantitative expression of trade-offs and synergies among ecosystem services}

Bivariate correlation analysis and Moran's I index were used to analyze the trade-offs and synergies among the four ecosystem services of water yield, carbon storage, soil retention, and food supply.

(1) Measure of trade-offs and synergies among ecosystem services

First, the amounts of the four ecosystem services in the unit of a town or a district were calculated using the Zonal Statistics function in ArcGIS 10.2. Second, the amounts of change in ecosystem services from 2000 to 2015 were calculated. In addition, the data were standardized to eliminate dimensional relationships between the various data. Finally, the standardized data were imported to SPSS for bivariate correlation analysis, which produced a correlation coefficient matrix among water yield, carbon storage, soil retention, and food supply.

(2) Spatial expression of trade-offs and synergies among ecosystem services 
First, the Weight module in the GeoDA software was used to establish a spatial weight matrix. Then, the bivariate local Moran's I module was used to calculate the local autocorrelation Moran's I index among the ecosystem services. Finally, the map for the local indicators of spatial association (LISA) was drawn.

\section{Results}

\subsection{LUCC in the Pearl River Delta}

In both 2000 and 2015, woodland was the main land use type in the Pearl River Delta, constituting $56.62 \%$ and $55.19 \%$ of the region's total area, respectively (Figure 2), most of which was distributed in Zhaoqing, Huizhou, and northern regions of Guangzhou. In comparison, the proportion of cropland was relatively small, accounting for $26.48 \%$ and $22.65 \%$ of the total area in 2000 and 2015, respectively, which was mainly distributed in the central region of the Pearl River Delta. In 2000, built-up land was concentrated primarily in central and western parts of Guangzhou and southern part of Shenzhen, with sporadic distribution in Dongguan. However, by 2015, the expansion of built-up land in the Pearl River Delta was considerable, especially in central areas such as Guangzhou and Dongguan. In 2000 and 2015 , the total area of water body, grassland, and unused land was small.

During 2000 to 2015, land use types in the Pearl River Delta underwent considerable change. Table 1 shows the land use and land cover change from 2000 to 2015 in detail. The areas of cropland, woodland, water body, and unused land decreased, while the areas of grassland and built-up land increased. During 2000 to 2015, the total area of cropland in the Pearl River Delta decreased by $2067.17 \mathrm{~km}^{2}$, which represents the largest area reduction $(14.46 \%)$ of all land use types. The largest reductions in cropland area occurred in Guangzhou, Dongguan, and Foshan. During 2000-2015, the total area of woodland in the Pearl River Delta decreased by $773.00 \mathrm{~km}^{2}$ with the largest reduction in area in Dongguan. During the same period, the water body area also decreased by $326.03 \mathrm{~km}^{2}$. Conversely, during 2000-2015, the area of built-up land in the Pearl River Delta increased by $3144.14 \mathrm{~km}^{2}$ $(77.33 \%)$. The largest area of increase was observed in Guangzhou, Dongguan, and Foshan. The second largest increase in area of land use was grassland, which increased by $23.65 \mathrm{~km}^{2}$ (2.50\%). Overall, rapid expansion of built-up land and rapid reduction in cropland represent the main features of land use change in the Pearl River Delta during 2010-2015.

During the study period, conversion among land use types affected mainly grassland, cropland, built-up land, woodland, and water body, and conversion involving unused land was minimal. The areas of cropland, woodland, and water body transferred to built-up land during 2000-2015 were 1765.01, 806.18, and $599.30 \mathrm{~km}^{2}$, respectively, and these changes occurred mainly in central areas of the Pearl River Delta, i.e., Guangzhou, Foshan, Dongguan, and other cities. During the same period, the conversions of woodland to cropland and of water body to cropland were 118.51 and $56.90 \mathrm{~km}^{2}$, respectively. In addition, $126.46 \mathrm{~km}^{2}$ of woodland was transferred to grassland and $227.96 \mathrm{~km}^{2}$ of cropland and $45.80 \mathrm{~km}^{2}$ of grassland were converted to woodland. The conversions of other land use types to woodland, cropland, and grassland reflect the success of strengthened environmental protection in Guangdong Province. 


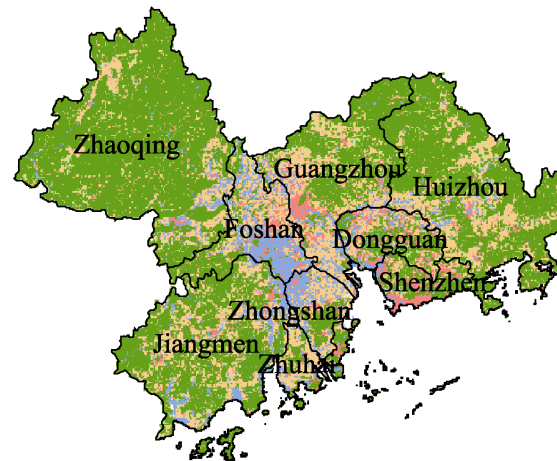

(a) 2000

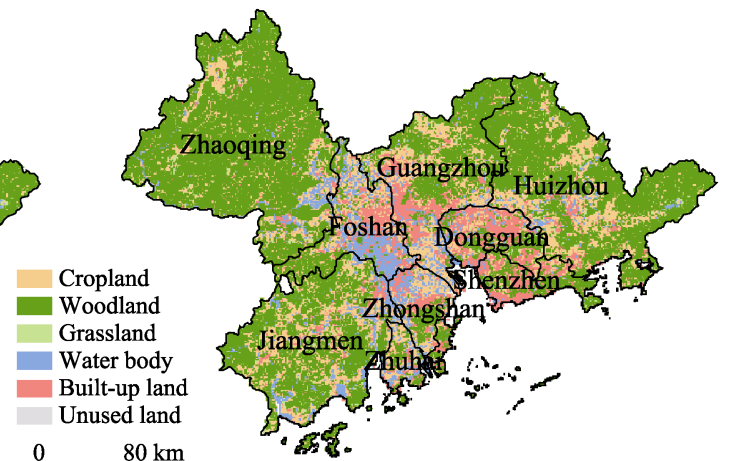

(b) 2015

Figure 2 The Pearl River Delta land use map from 2000 to 2015

Table 1 Land-use structure and its transfer matrix of in the Pearl River Delta from 2000 to $2015\left(\mathrm{~km}^{2}\right)$

\begin{tabular}{|c|c|c|c|c|c|c|c|c|}
\hline & \multirow{2}{*}{ Land use } & \multicolumn{6}{|c|}{2015} & \multirow{2}{*}{ Total } \\
\hline & & Cropland & Woodland & Grassland & Water body & Built-up land & Unused land & \\
\hline \multirow{7}{*}{2000} & Cropland & 12007.96 & 227.96 & 8.50 & 285.46 & 1765.01 & 1.38 & 14296.27 \\
\hline & Woodland & 118.51 & 29477.28 & 126.46 & 44.27 & 806.18 & 0.78 & 30573.48 \\
\hline & Grassland & 3.17 & 45.80 & 827.54 & 0.09 & 67.74 & & 944.34 \\
\hline & Water body & 56.90 & 22.49 & 4.39 & 3405.61 & 599.30 & 0.00 & 4088.69 \\
\hline & Built-up land & 42.50 & 26.76 & 1.10 & 26.37 & 3969.27 & & 4066.00 \\
\hline & Unused land & 0.06 & 0.19 & & 0.86 & 2.64 & 22.12 & 25.87 \\
\hline & Total & 12229.10 & 29800.48 & 967.99 & 3762.66 & 7210.14 & 24.28 & 53994.65 \\
\hline
\end{tabular}

\subsection{Spatiotemporal heterogeneity and influencing mechanism of ecosystem services}

The values of the four ecosystem services in the Pearl River Delta changed considerably from 2000 to 2015. Water yield and carbon storage showed increasing trends, whereas soil retention and food supply showed decreasing trends (Table 2).

Table 2 Ecosystem services change in the Pearl River Delta from 2000 to 2015

\begin{tabular}{lcccc}
\hline Year & Water yield $\left(\times 10^{8} \mathrm{~m}^{3}\right)$ & Carbon storage $\left(\times 10^{4} \mathrm{t}\right)$ & Soil retention $\left(\times 10^{8} \mathrm{t}\right)$ & Food supply $\left(\times 10^{4} \mathrm{t} / \mathrm{km}^{2}\right)$ \\
\hline 2000 & 734.82 & 61984.81 & 40.53 & 601.15 \\
2015 & 745.49 & 62242.02 & 40.46 & 291.71 \\
Change & 10.67 & 257.21 & -0.07 & -309.44 \\
ESCI & $(-0.37,0.76)$ & $(-1,0.29)$ & $(-0.29,0.42)$ & $(-0.69,-0.18)$ \\
\hline
\end{tabular}

Note: ESCI represents an increase or decrease in each ecosystem service. It indicates increase in ecosystem services when ESCI $>0$, otherwise it represents decrease, and it indicates unchange when ESCI $=0$.

(1) Water yield. Regions with high values of water yield were found to be located in eastern, central, and western coastal parts of the Pearl River Delta (Figures $3 \mathrm{a}$ and 3b). From 2000 to 2015 , water yield in the Pearl River Delta increased by $10.67 \times 10^{8} \mathrm{~m}^{3}$. The main 
area of increase was in central regions of the Pearl River Delta, including Guangzhou, Foshan, Dongguan, Zhongshan, and Shenzhen (Figure 3c). From the perspective of LUCC, the change in water yield was attributable mainly to woodland, including broad-leaved forests with considerable capacity for water evapotranspiration, because this was the main land use type in the Pearl River Delta during the study period. During the study period, large amounts of woodland were converted to other land use types such as cropland and grassland, which caused water evapotranspiration to decrease and water yield to increase.

(2) Carbon storage. The areas with high values of carbon storage were found to be distributed in eastern and western parts of the Pearl River Delta, while central areas had low values (Figures 3d and 3f). From 2000 to 2015, carbon storage increased from 61,984.81 $\times$ $10^{4}$ to $62,242.02 \times 10^{4} \mathrm{t}$, i.e., an increase of $257.21 \times 10^{4} \mathrm{t}$. As one of the most important carbon pools on land, an increase in the area of grassland will increase regional carbon storage (Li et al., 2014). From 2000 to 2015, the grassland area in the study region increased by $23.65 \mathrm{~km}^{2}$. In addition, built-up land generally also includes a certain proportion of artificial urban greening, which could have higher carbon density than a semi-artificial cropland ecosystem (Wei et al., 2014). During 2000-2015, $1765.01 \mathrm{~km}^{2}$ of cropland were converted to built-up land through Pearl River Delta urbanization, which had a certain impact on the increase of carbon storage.

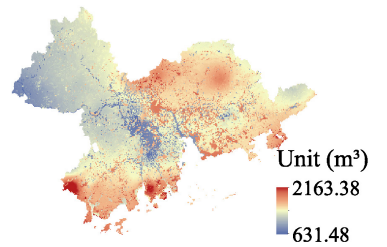

(a) Water yield in 2000

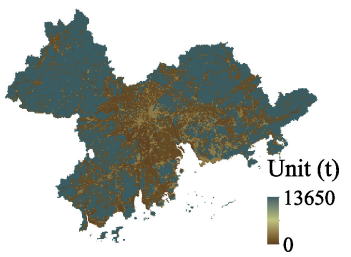

(d) Carbon storage in 2000

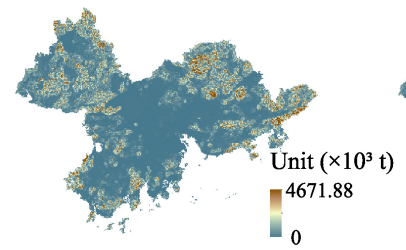

(g) Soil retention in 2000

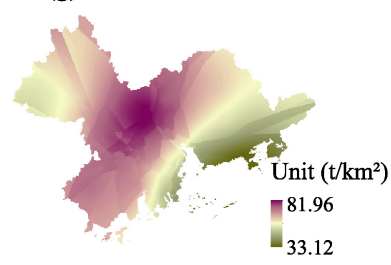

(j) Food supply in 2000

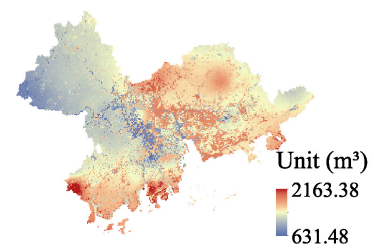

(b) Water yield in 2015

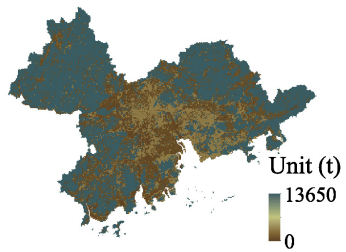

(e) Carbon storage in 2015

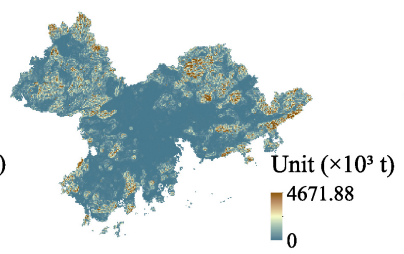

(h) Soil retention in 2015

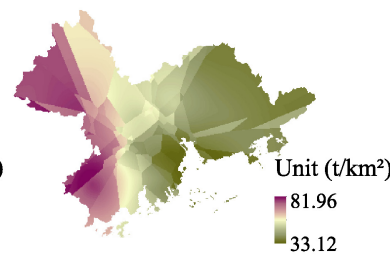

(k) Food supply in 2015

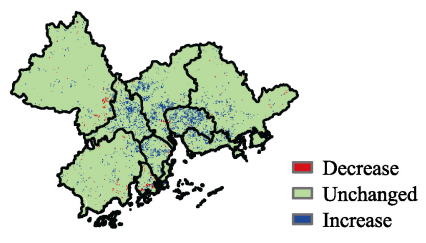

(c) Change of water yield from 2000 to 2015

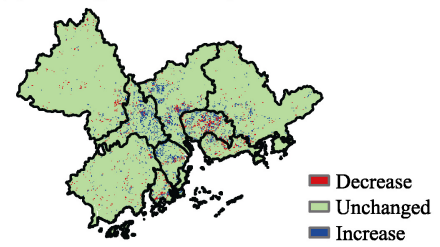

(f) Change of carbon storage from 2000 to 2015

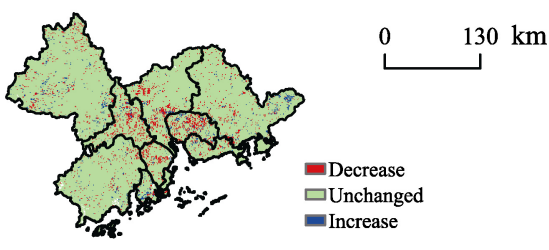

(i) Change of soil retention from 2000 to 2015

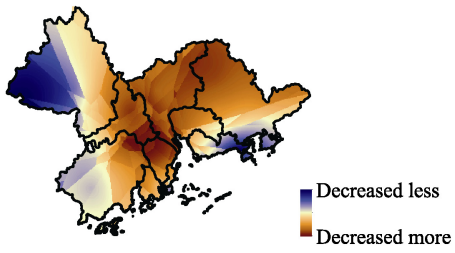

(1) Change of food supply from 2000 to 2015

Figure 3 Spatial distribution and change of ecosystem services in the Pearl River Delta from 2000 to 2015 
(3) Soil retention. As is well known, the reduction of woodland and cropland can result in diminished coverage of ground-level vegetation. This situation will reduce the ability of woodland to intercept rainfall via the canopy, litter, and soil layers and reduce the ability of crops to resist soil erosion by rain. Therefore, because of the decline of woodland and cropland during the study period, the soil retention of the Pearl River Delta decreased by $0.07 \times$ $10^{8} \mathrm{t}$. Regionally, the main areas of decrease in soil retention were found in central Foshan, Zhongshan, Dongguan, and Guangzhou (Figure 3i), indicating increased soil erosion in these areas.

(4) Food supply. Food supply decreased by $309.44 \mathrm{t} / \mathrm{km}^{2}$ from 2000 to 2015 . This occurred mainly in central parts of the Pearl River Delta, including Guangzhou, Foshan, and Zhongshan. The rate of urbanization in the Pearl River Delta was $71.60 \%$ in 2000 and $84.90 \%$ in 2016; consequently, large amounts of cropland were transferred to built-up land and areas of dike-pond were lost in meeting the needs of the population and economic development. In summary, the capacity of the food supply dropped significantly during the study period.

\subsection{Trade-offs/synergies and influencing mechanisms among ecosystem services}

Table 3 shows the results of the bivariate correlation analysis and Moran's I index among the four ecosystem services investigated in this study. In terms of temporal dynamics (R), positive correlations found between water yield and carbon storage, carbon storage and soil retention, carbon storage and food supply, and soil retention and food supply indicate synergies between these pairs of ecosystem services. Water yield was found correlated negatively with soil retention and food supply, which indicates trade-offs in these relationships. The correlation coefficient between water yield and carbon storage $(0.632$; passing the test of significance at the 0.01 level) indicates significant synergy among these ecosystem services. The reason is that water is evaporated into water vapor and then returned to the Pearl River Delta in the form of precipitation, which can promote woodland and grassland growth and increase carbon storage capacity via sequestration. This is why an increase in regional water yield will improve carbon storage. The most significant negative correlation was found between water yield and food supply ( -0.334 ; passing the test of significance at the 0.01 level), indicating significant trade-offs among these ecosystem services. The trade-offs were caused by the rapid expansion of built-up land and the invasion of cropland in the Pearl River Delta during the study period, which meant the region had an increased capacity of water yield but

Table 3 Relationship among ecosystem services of the Pearl River Delta

\begin{tabular}{|c|c|c|c|c|c|c|c|c|c|c|c|}
\hline \multirow[t]{2}{*}{$\begin{array}{c}\text { Ecosystem } \\
\text { services }\end{array}$} & \multicolumn{3}{|c|}{ Water yield } & \multicolumn{2}{|c|}{ Carbon storage } & \multicolumn{4}{|c|}{ Soil retention } & \multicolumn{2}{|c|}{ Food supply } \\
\hline & $R$ & Moran's I & Re. & $R$ & Moran's I & Re. & $R$ & Moran's I & Re. & $R$ & Moran's I \\
\hline Water yield & 1 & & & & & & & & & & \\
\hline Carbon storage & $0.632^{* *}$ & 0.115 & $\mathrm{~S}$ & 1 & & & & & & & \\
\hline Soil retention & $-0.294^{* *}$ & 0.014 & $\mathrm{~T} / \mathrm{S}$ & 0.069 & 0.086 & $\mathrm{~S}$ & 1 & & & & \\
\hline Food supply & $-0.334^{* *}$ & -0.007 & $\mathrm{~T}$ & 0.035 & 0.065 & $\mathrm{~S}$ & $0.332^{* *}$ & 0.200 & $\mathrm{~S}$ & 1 & \\
\hline
\end{tabular}

Note: $R$ represents correlation coefficient; Moran's I represents Moran's I index; Re. represents relationship between each double variables; ${ }^{* *}$ represents significant correlation at the 0.01 level (both sides); $\mathrm{S}$ represents synergies; T represents trade-offs. 
a diminished capacity of food supply. Spatially (Moran's I index), the trade-offs/synergies of ecosystem services in the Pearl River Delta were established as follows. Soil retention and carbon storage, soil retention and food supply, and carbon storage and water yield all showed synergies but the synergies were weak on the spatial scale. Food supply and carbon storage showed weak synergies on both temporal and spatial scales. The relationship of trade-offs/synergies between water yield and food supply was unclear because the value of Moran's I index was small.

The spatial clustering characteristics for the four aforementioned ecosystem services in the Pearl River Delta area are shown in Figure 4. It can be seen that the relationship of trade-offs/synergies among the various ecosystem services in the Pearl River Delta between 2000 and 2015 had reasonably significant spatial heterogeneity. (1) The regions with synergies between water yield and food supply were found distributed in central and western parts of Zhaoqing, northern parts of Guangzhou, and western parts of Jiangmen. The regions with trade-offs among these ecosystem services were found distributed mainly in Dongguan and Zhongshan (Figure 4a). (2) Trade-offs between carbon storage and water yield were found mainly in northern parts of Zhaoqing and the south of Jiangmen (Figure 4b), while synergies were found mainly in Foshan and central and western parts of Zhaoqing. (3) Trade-offs between water yield and soil retention were found mainly in Huizhou and Zhongshan, while

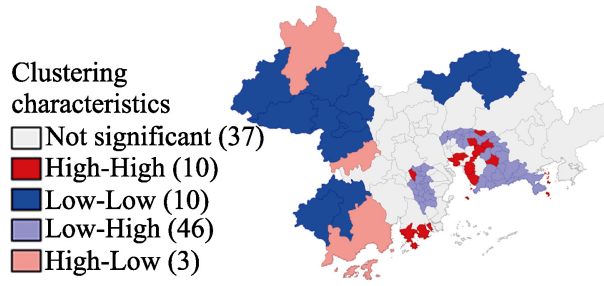

(a) Water yield-food supply

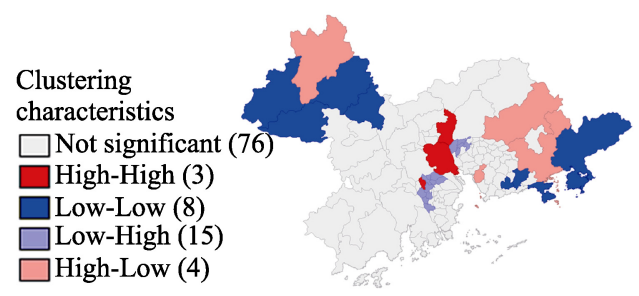

(c) Soil retention-water yield

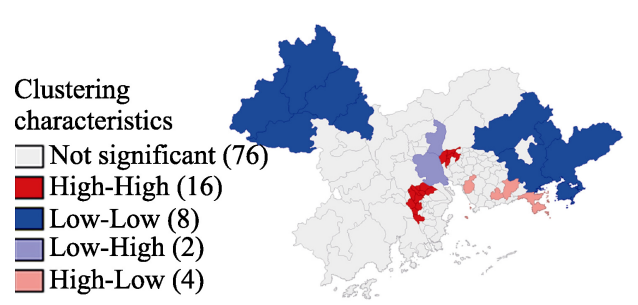

(e) Soil retention-food supply

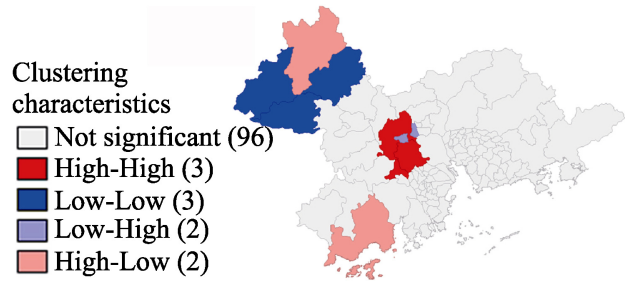

(b) Carbon storage-water yield

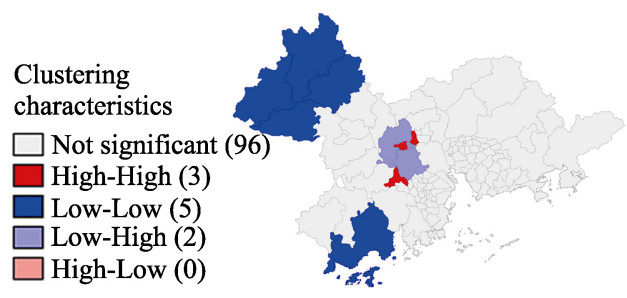

(d) Food supply-carbon storage

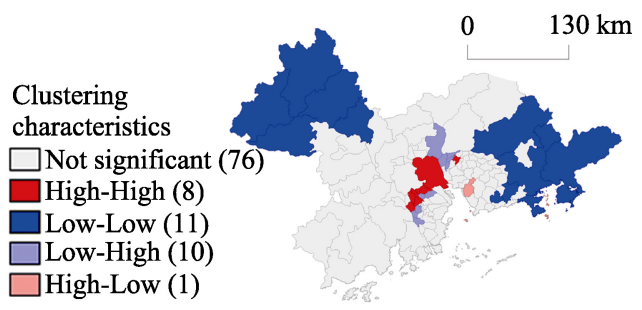

(f) Carbon storage-soil retention

Figure 4 Spatial trade-offs/synergies between four ecosystem services in the study are: High-High and Low-Low represent synergies, while Low-High and High-Low represent trade-offs, numbers in the brackets indicate the number of towns/districts. 
synergies were found in southern parts of Guangzhou and central and western parts of Zhaoqing (Figure 4c). (4) Synergies between soil retention and food supply and between carbon storage and soil retention were found primarily on the spatial scale and their spatial distributions were similar, i.e., mainly in Zhaoqing and Huizhou, while trade-offs between these pairs of ecosystem services were found mainly in the middle of the Pearl River Delta (Figures 4d and 4e). (5) Synergies between food supply and carbon storage were found distributed mainly in Zhaoqing and the south of Jiangmen, while their areas of trade-offs were small and found distributed mainly in Foshan (Figure 4f).

\section{Discussion}

\subsection{Effect of LUCC on ecosystem services}

Through analysis of both the LUCC in the Pearl River Delta from 2000 to 2015 and the spatiotemporal heterogeneity of the four ecosystem services, we found that changes in woodland, grassland, cropland, and built-up land were the main mechanisms of influence of the spatiotemporal heterogeneity of ecosystem services. This study also analyzed the relationships of trade-offs/synergies among the four ecosystem services in the Pearl River Delta. Negative correlation (trade-offs) was found between the two provisioning services (water yield and food supply), while positive correlation (synergies) was found between the two regulating services (carbon storage and soil retention). The relationships between the provisioning and regulating services have both trade-offs and synergies. The correlation coefficient of -0.294 between water yield and soil retention indicated trade-offs. The trade-offs found between this pair of ecosystem services are contrary to the results of most other studies. For example, Qian et al. (2018) found significant synergies between water yield and soil retention (correlation coefficient: 0.551) in their study of the Bailong River Basin in Gansu Province. Wu et al. (2017) also found significant synergies between water yield and soil retention in 2000 and 2015 ( 0.972 and 0.771, respectively) in the city of Erdos, China. From the perspective of LUCC, the reason for this difference could be that the areas of the Pearl River Delta in which water yield increased were approximately the same as those in which soil retention reduced, i.e., in central parts of the Pearl River Delta with high levels of urbanization and rapid economic development. Therefore, given the needs of economic development and population growth, considerable areas of woodland, cropland, and grassland in the Pearl River Delta were transferred to built-up land, which increased the area of impervious ground in urban areas, changed the water balance, reduced infiltration, and ultimately increased water yield. Furthermore, both the interception capacity of the surface and the capacity of soil retention were reduced because of the reduction in areas of woodland, grassland, and cropland. However, the four ecosystem services in the Pearl River Delta were found dominated by synergies on both temporal and spatial scales, which could be beneficial for the development of ecological restoration and protection policies in the Pearl River Delta. Therefore, this analysis of the spatiotemporal heterogeneity of ecosystem services from the perspective of LUCC not only provides a reference for the ecological management of the Pearl River Delta but also constitutes a basis for decision makers in relation to land management.

\subsection{Applicability and limitations}

The InVEST model was used in this study to assess the quality of four typical ecosystem 
services in the Pearl River Delta during 2000-2015. The results revealed that the water yield modulus in the Pearl River Delta in 2015 was $136.12 \times 10^{4} \mathrm{~m}^{3} / \mathrm{km}^{2}$, similar to the value of $114.41 \times 10^{4} \mathrm{~m}^{3} / \mathrm{km}^{2}$ published in the Guangdong Province Water Resources Bulletin 2015 (2015). Similarly, according to data published by the Pearl River Water Resources Commission (PRWRC, 2007), the average annual water loss and soil erosion modulus of the Pearl River Basin was $2795 \mathrm{t} / \mathrm{km}^{2}$ in the second national soil erosion remote sensing survey in 2000. However, the water losses and soil erosion modulus of the Pearl River Delta in 2000 and 2015 were found in this study to be 3009.74 (relative error: 7\%) and $3132.41 \mathrm{t} / \mathrm{km}^{2}$ (relative error: $12 \%$ ), respectively. Although the relative errors of water losses and soil erosion modulus in the two periods are small, they are higher than the average value published by the PRWRC. The main reasons for the differences are as follows. (1) The Pearl River Basin includes the provinces of Yunnan, Guizhou, Guangxi, and Guangdong but this study considered only the Pearl River Delta in Guangdong Province. The annual average precipitation of the Pearl River Delta is more than other regional river basins, and the speed of urbanization development is faster than in other surrounding provinces. Large amounts of woodland, cropland, and grassland in the Pearl River Delta were transferred to built-up land, which caused increased serious soil erosion. (2) The method adopted in the second national soil erosion remote sensing survey was an all-digital operation that used human-computer interaction mapping and direct generation of mapped areas, different to the method used in the soil retention module based on the USLE. Thus, the water losses and soil erosion modulus of the Pearl River Delta was higher than the average value. In summary, comparison of the evaluation results from the InVEST model with actual data published by the government reveals that the InVEST model has satisfactory applicability to the evaluation of ecosystem services in the Pearl River Delta.

Despite the established applicability of the InVEST model, certain limitations remain. (1) The water yield module does not differentiate between surface, subsurface, and baseflow; instead, it assumes the water yield from a pixel reaches the point of interest via one of these pathways. Thus, the water yield module ignores the influence of factors such as fog, groundwater, and the type and seasonal variation of plant leaf on water yield, which leads to certain deviation between the evaluated and measured values. (2) The carbon storage module simplifies the carbon cycle, which allows it to run with reasonably little information but leads to important limitations. Moreover, the module assumes that none of the LUCC types within a landscape gains or loses carbon over time, which will reduce the evaluation accuracy of carbon storage to some extent. (3) The spatial precision of the land use data used in this study was reasonably poor, which will also affect the research results.

This study analyzed the heterogeneity and mechanisms of ecosystem services in the Pearl River Delta from the perspective of LUCC, and the derived results have certain importance in relation to land management and ecosystem services protection. However, only four types of ecosystem services were studied and thus the results have certain limitations. Moreover, LUCC in the Pearl River Delta over a period of only 15 years was considered. In future work, it will be necessary to simulate future urban change and to quantify other ecosystem services (e.g., habitat quality and biodiversity). This would encourage government to pay attention to all ecosystem services when formulating relevant policies, to maintain ecological balance and ensure sustainable development of the economy and ecosystem. 


\section{Conclusions}

We explored land use change in the Pearl River Delta from 2000 to 2015 and assessed its impact of LUCC on the heterogeneity of ecosystem services. There are some conclusions as follows:

(1) Rapid expansion in built-up land $\left(3144.14 \mathrm{~km}^{2}\right)$ and sharp reduction in cropland $\left(2067.17 \mathrm{~km}^{2}\right)$ were the major causes for land use change in the Pearl River Delta during 2010-2015. Various land uses, of which the largest area transferred is that of cropland $\left(1765.01 \mathrm{~km}^{2}\right)$, have been transferred to built-ups. Cropland shrinking mainly occurred in the central part of the Pearl River Delta due to fast urbanization there.

(2) LUCC played an inherently strong role in the spatiotemporal heterogeneity of ecosystem services, characterized by increasing in water yield and carbon storage $\left(10.67 \times 10^{8} \mathrm{~m}^{3}\right.$ and $257.21 \times 10^{4} \mathrm{t}$ respectively) and decreasing in soil retention and food supply $\left(0.07 \times 10^{8}\right.$ $\mathrm{t}$ and $309.44 \mathrm{t} / \mathrm{km}^{2}$ respectively). The ESCI for the four ecosystem services fluctuated each year from 2000 to 2015, revealing that the rapid economic development and urbanization in the Pearl River Delta, on some level, was at the expense of ecosystem services.

(3) Because the various ecosystem services were affected by land use change, trade-off/synergy effects were ubiquitous between them, for example, trade-offs between the two provisioning services (water yield and food supply), and synergies between the two regulating services (carbon storage and soil retention). The combination of provisioning and regulating services showed both trade-offs and synergies in their temporal patterns, but with a significant spatial heterogeneity. Therefore, management strategies should be formulated to keeping a reasonable configuration pattern for different land uses and balance between comprehensive ecosystem services.

\section{References}

Braat L C, Brink P T, Klok T C, 2008. Cost of Policy Inaction-COPI: The Case of Not Meeting the 2010 Biodiversity Target. Alterra: EU/IEEE Publication.

Budyko M I, 1974. Climate and Life. New York: Academic Press.

Butsic V, Shapero M, Moanga D et al., 2017. Using InVEST to assess ecosystem services on conserved properties in Sonoma County, CA. California Agriculture, 71(2): 81-89.

Costanza R, d'Arge R, Groot R D et al., 1997. The value of the world's ecosystem services and natural capital. Nature, 387(6630): 253-260.

Daily G C, 1997. Nature's Services: Societal Dependence on Natural Ecosystems. Washington D C: Island Press.

Di Sabatino A, Coscieme L, Vignini P et al., 2013. Scale and ecological dependence of ecosystem services evaluation: Spatial extension and economic value of freshwater ecosystems in Italy. Ecological Indicators, 32(9): 259-263.

Droogers P, Allen R G, 2002. Estimating reference evapotranspiration under inaccurate data conditions. Irrigation and Drainage Systems, 16(1): 33-45.

Fu B J, Wang S, Liu Y et al., 2016. Hydrogeomorphic ecosystem responses to natural and anthropogenic changes in the Loess Plateau of China. Annual Review of Earth and Planetary Sciences, 45(1): 223-243.

Fu B J, Zhang L W, 2014. Land-use change and ecosystem services: Concepts, methods and progress. Progress in Geography, 33(4): 441-446. (in Chinese)

Fu B J, Zhou G Y, Bai Y F et al., 2009. The main terrestrial ecosystem services and ecological security in China. Advances in Earth Science, 24(6): 571-576. (in Chinese)

Gan H H, Wu S H, Fan X D, 2003. Reserves and spatial distribution characteristics of soil organic carbon in Guangdong Province. Chinese Journal of Applied Ecology, 14(9): 1499-1502. (in Chinese)

Li S C, Zhang C Y, Liu J L et al., 2013. The tradeoffs and synergies of ecosystem services: Research progress, development trend, and themes of geography. Geographical Research, 32(8): 1379-1390. (in Chinese)

Li X B, Fan R X, Liu X D, 2014. Advance in studies on carbon storage and carbon process in grassland ecosystem 
of China. Ecology and Environmental Sciences, 23(11): 1845-1851. (in Chinese)

Li Y F, Luo C Y, Liu G et al., 2013. Effects of land use change on ecosystem services: A case study in Miyun reservoir watershed. Acta Ecologica Sinica, 33(3): 726-736. (in Chinese)

Liu Z J, Liu Y S, Baig M H A, 2018a. Biophysical effect of conversion from croplands to grasslands in water-limited temperate regions of China. Science of the Total Environment, 648: 315-324.

Liu Z J, Liu Y S, Li Y R, 2018b. Extended warm temperate zone and opportunities for cropping system change in the Loess Plateau of China. International Journal of Climatology, 1-12.

Leh M D K, Matlock M D, Cummings E C et al., 2013. Quantifying and mapping multiple ecosystem services change in West Africa. Agriculture Ecosystems and Environment, 165: 6-18.

Millennium Ecosystem Assessment (MA), 2005. Ecosystems and Human Well-being: Current State and Trends. Washington D C: Island Press.

Ouyang Z Y, Zheng H W, Xiao Y et al., 2016. Improvements in ecosystem services from investments in natural capital. Science, 352(6292): 1455-1459.

Peng J, Hu X X, Zhao M Y et al., 2017. Research progress on ecosystem service trade-offs: From cognition to decision-making. Acta Geographica Sinica, 72(6): 960-973. (in Chinese)

Pearl River Water Resources Commission (PRWRC), 2007. Soil and water loss in the Pearl River, viewed 09/03/2011. http://www.pearlwater.gov.cn/zjstbc/lsgk/201103/t20110309_40944.htm.

Qian C Y, Gong J, Zhang J X et al., 2018. Change and tradeoffs-synergies analysis on watershed ecosystem services: A case study of Bailongjiang Watershed, Gansu. Acta Geographica Sinica, 73(5): 868-879. (in Chinese)

Renard K G, Foster G R, Weesies G A et al., 1997. Predicting soil erosion by water: A guide to conservation planning with the Revised Universal Soil Loss Equation (RUSLE). Agriculture Handbook No.703. USDA, Agricultural Research Service, Washington, DC.

Rodríguez J P, Beard Jr T D, Bennett E M et al., 2006. Trade-offs across space, time, and ecosystem services. Ecology and Society, 11(1): 709-723.

Roose E, 1996. Land husbandry: Components and strategy. FAO Soils Bulletin. 70, Rome: Food and Agriculture Organization of the United Nations.

Sharpley A N, Williams J R, 1990. EPIC: The erosion-productivity impact calculator: 2. User manual. Technical Bulletin-United States Department of Agriculture, 4(4): 206-207.

Tallis H T, Ricketts T, Guerry A D et al., 2011. InVEST 2.1 beta User's Guide. Stanford: The Natural Capital Project.

Tang Y, Zhu W P, Zhang H et al., 2015. A review on principle and application of the InVEST model. Ecological Science, 34(3): 204-208. (in Chinese)

Vidal-Legaz B, Martínez-Fernández J, Picón A S et al., 2013. Trade-offs between maintenance of ecosystem services and socio-economic development in rural mountainous communities in southern Spain: A dynamic simulation approach. Journal of Environmental Management, 131(1): 280-297.

Wang W Z, Jiao J Y, He X P et al., 1995. Study on rainfall erosivity in China. Journal of Soil and Water Conservation, (4): 7-18. (in Chinese)

Water Resources Department of Guangdong Province, 2016. Guangdong Province Water Resources Bulletin 2015, Nan Fang Daily, 12/08/2016(A05). (in Chinese)

Wei Z Q, Wu S H, Zhou S L et al., 2014. Soil organic carbon transformation and related properties in urban soil under impervious surfaces. Pedosphere, 24(1): 56-64.

Wu P J, Liu X P, Li X et al., 2016. Impact of urban expansion on carbon storage in terrestrial ecosystems based on InVEST model and CA: A case study of Guangdong Province, China. Geography and Geo-Information Science, 32(5): 22-28, 36, 2. (in Chinese)

Wu R S, Guan D S, 2006. Spatio-temporal variation of population and its influence on the resources and environment in Pearl River Delta. Chinese Journal of Ecology, 25(12): 1586-1590. (in Chinese)

Wu W H, Peng J, Liu Y X et al., 2017. Tradeoffs and synergies between ecosystem services in Ordos City. Progress in Geography, 36(12): 1571-1581. (in Chinese)

Xu Q Y, Huang M, Liu H S et al., 2011. Integrated assessment of eco-environmental vulnerability in Pearl River Delta based on RS and GIS. Chinese Journal of Applied Ecology, 22(11): 2987-2995. (in Chinese)

Yang D Y, 2011. Pearl River Delta economic zone ecological environment problems and countermeasures. Urban Studies, 18(8): 59-63. (in Chinese)

Ye C S, Feng Y F, 2013. Ecological risk assessment for Pearl River Delta based on land use change. Transactions of the Chinese Society of Agricultural Engineering, 29(19): 224-232+294. (in Chinese)

Zhang X Y, Xu Z C, Zeng F T et al., 2011. Carbon density distribution and storage dynamics of forest ecosystem in Pearl River Delta of low subtropical. China Environmental Science, 31(Suppl.1): 69-77. (in Chinese)

Zhou C S, Dai D D, 2015. Transition of urbanization in the Pearl River Delta. Tropical Geography, 35(3): 343-353. (in Chinese) 